\title{
Study of Railway Steel Bridges' Behaviour in Order to Identify the Causes of Their Defects
}

\author{
Serhii Kliuchnyk, Pavlo Ovchynnykov
}

Dep. “Transport infrastructure”, Dnipro National University of Railway Transport named after Academician V. Lazaryan, Lazaryana st. 2, Dnipro, Ukraine, 49010, e-mails: serhij_klyuchnyk@diit.edu.ua, pavlo_ovchynnykov@diit.edu.ua

\begin{abstract}
The purpose of this work is to clarify the causes and mechanism of premature origin of defects in the elements of the bridge deck with the storey connection in steel span structures of railway bridges by studying the stress-strain state of their deck beams. Research aimed at extending the service life and increasing the carrying capacity of metal girder structures with a low load class and at the introduction of a new design solution for connecting the nodes of the deck beams, which is extremely important to ensure the necessary railway capacity and train safety. Service life and reliability of stringer beams of a deck definitively defines a service life and carrying capacity of all span structure. In order to deepen the analysis of the experimental data of the tested structures, calculations of the structure with the initial data, that fully correspond to the experimental span structure, were performed. For theoretical researches the underslung span structure with through trusses, designed by "Proektstalkonstruktsiya" with the nominal span of $L n=44,0 \mathrm{~m}$ with a storey carriageway was chosen, as the one having the greatest number of defects in nodes of stringers support by the floor beams. According to the results of calculations and computer simulations, it is determined that the main cause of cracks is the structural imperfection of the aforementioned nodes, that is typical of similar structures.
\end{abstract}

Keywords: railway bridge; bridge deck; storey connection; stress-strain state; truss bridge

\section{Introduction}

After WWII the development of bridge infrastructure occurred using girder structures designed by "Proektstalkonstruktsiya" ("Project-steel-construction", PSC). Dynamic construction of artificial structures - around 1550 bridges constructed - occurred during the country's rebuilding period - from 1946 to 1962. These structures were designed to save materials using lightweight design load standards that do not meet modern requirements. On the railways of Ukraine at present almost $13 \%$ of metal girder structures are considered defective, and about $47 \%$ have an insufficient load class [1], so the issue of determining the real operational resource of girder structures and determining ways to increase it 
becomes especially relevant. Improving the reliability of bridges is one of the main tasks of the track network maintenance, as bridges are the most responsible and complex elements of roads. In fact, it is the bridges that determine the bearing capacity of the tracks [2].

\section{General Characteristics of Girder Structures according to PSC Projects}

In 1944, the design bureau "Projectsteelconstruction" (PSC) in conditions when in a short time it was necessary to manufacture and install on bridges an extremely large number of destroyed metal girder structures, proposed new standard designs of truss girder structures with riding at the level of the top and bottom chords (deck-type and through-type) [3].

The design of the truss structures of the PSC (general diagrams, type of truss gratings, cross-sectional shapes of truss elements, construction of assemblies, joints, etc.) was unified for the manufacture of structures at the factory using machine riveting and maximum unification. Rated load of PSC girders is N7.

Characteristic features of the underslung girder structures of PSC are the reduction of the distance between the main trusses to $4.0 \mathrm{~m}$, the use of cross ties of the main trusses and change of the deck beams design, which adopted the storey connection of stringers $(\mathrm{S})$ and floor beams $(\mathrm{F})[4,5]$. The design of the support of the stringers on the floor beams is shown in Figure 1.

For PSC span structures with a storey connection of deck beams the main defects and disorders are:

- loosening and rupture of vertical rivets or bolts attaching stringers to the floor beams;

- loose bearings of stringers by floor beams that leads to more intensive wear of metal and increase in dynamic action of a rolling stock;

- longitudinal cracks in the bottom flange angles of the stringers along the corners of the angles at their end segments;

- increasing the length of cracks and the appearance of punctures with complete separation of the horizontal edge of the stringers' flange angles;

- cracks along the corners of the top flange angles of the floor beams in the places of the stringers' bearing;

- punching horizontal edges of the top flange angles of the floor beams in the area of stringers' support. 


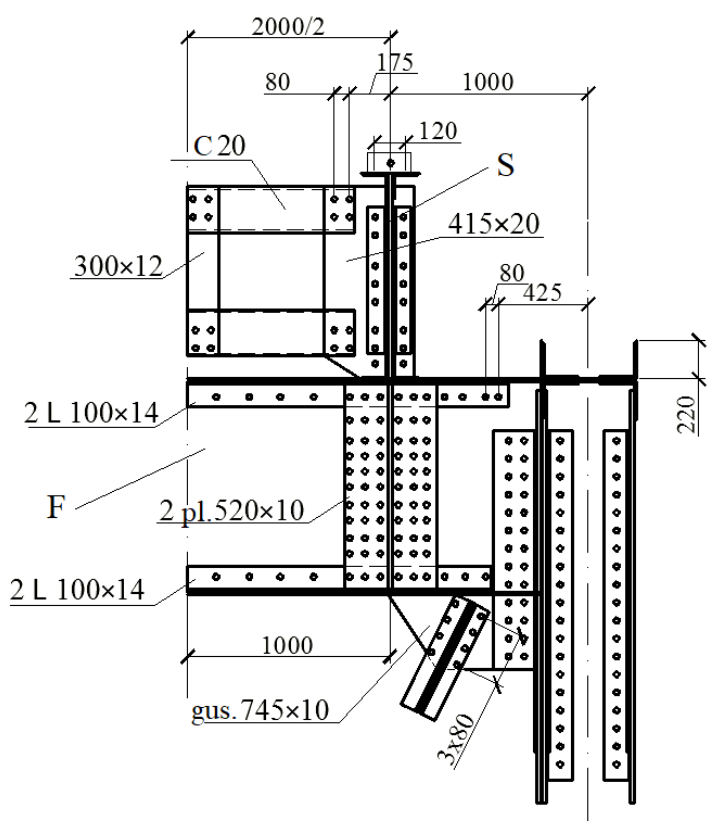

Figure 1

Design of the deck beams of the underslung PSC girder structures ( $\mathrm{S}$ - stringer, $\mathrm{F}$ - floor beam)

For all girder structures, defective rivets attaching the stringers to the floor beams are replaced by high-strength bolts, which in most joints are not tightened, and in many places the bearing of the stringers by the floor beams is loosened with a gap up to 1.5-2.5 $\mathrm{mm}$ between the "fish-gussets" of the stringers and top flange angles of the floor beams. At passage of a rolling stock specified clearances are closed and "splashes" and wear of metal are observed. At the same time, it should be noted that at full tightening of bolts conditions occur that facilitate the emergence of local overstrains and cracks in the bottom flange angles of stringers and top ones of the floor beams in the conditions of a variable and alternating cycles of loadings.

The issue of increasing the reliability of the elements of railway and highway bridges is one of the most pressing [6,7]. Fatigue cracks in the nodes of metal railway bridges appear in 3-20 years after the start of their operation [4, 5]. Operation of a bridge structure, with existence of fatigue damages in its nodes, can lead to restrictions in operation, decrease in loading capacity and an emergency condition of the whole structure. 


\section{Features of Deck Beams Work on Underslung Truss Structures}

According to modern design standards for metal bridges $[8,9]$ as well as earlier standards, calculation of springers and floor beams of a deck is usually carried out as for simple beams on two hinged supports considering the corresponding constant and temporary loadings. In real conditions the stringers work as continuous beams on elastic supports - floor beams. Floor beams, in turn, rest on the nodes of the main trusses, which under loads yield vertical and horizontal displacements.

The influence of vertical displacements (deflections of the main truss nodes) on the stress state of the deck beams is insignificant and therefore most often is not considered. As for the continuity of the stringers, it is considered approximately. Bending moments at the support section in stringers over floor beams when calculating strength are accepted at a rate of $60 \%$ of the maximum bending moments in the middle of stringers.

Horizontal longitudinal displacements of the main truss nodes, on which the floor beams rest, occur due to the deformation of the truss chords. As a result of coupled work of stringers with chords of the main trusses, floor beams of the deck are bent horizontally. The magnitudes of the horizontal bending moments in the floor beams decrease from the ends to the middle of the span structure and depend on the distance between the main trusses (mainly on the distance between the stringer and the closest truss) [3].

To reduce deformations and horizontal bending moments in the floor beams (for medium and large spans), deformation gaps in the stringers are arranged, and in modern projects - rigid diaphragms at the end sections of the span structures. In the latter case, a reliable inclusion (according to calculation) of the stringers in the coupled work with the respective chords of the main trusses. At the same time the difference of longitudinal deformation of chords of trusses and stringers considerably decreases and operational conditions of floor beams improve. In the conditions of storey connection of the deck beams due to occurrence of large eccentricity between axes of stringers and floor beams, operation of cross beams and bearing details of stringers becomes much more complicated, and overstress and cracks occur in beams' flange angles. Connecting rivets (or bolts) of fastening of stringers to floor beams also operate in difficult conditions.

When designing metal girder structures, the transverse impacts from the rolling stock are taken into account as $6 \%$ of the design load. With beams connection in one level, the arm of the given force from cross blows is small, and with storey connection of beams this arm increases considerably that also leads to complication of work of deck beams. 
In order to deepen the analysis of the work of the PSC girder structures, calculations were performed by the finite element method. For theoretical research the girder structure with through trusses of underslung type is taken, designed "Projectsteelconstruction" with the span of $\mathrm{Ln}=44,0 \mathrm{~m}$ with a storeyed deck. The specified truss is selected as the one with the largest number of defects in the nodes of the support of the stringer on the floor beam.

The assumption of the operation of the truss elements only on axial forces is based on the hypothesis of hinged nodes and nodal load transfer. In fact, due to inaccuracies in the centering of the elements in the nodes and the rigidity of the node connections, along with the axial forces in the truss rods, some bending moments occur. Bending moments cause additional stresses in the rods. These stresses are proportional to the linear stiffness of the elements adjacent to the nodes and, if the ratio of the heights of the elements to their length is more than $1 / 15$, then when calculating the trusses, the stiffness of the nodes is considered [ 8 , $9,3]$.

Calculations were performed for the spatial truss span structure. This calculation scheme considers the rigidity of the nodes and most of the design features of the actual span structure.

The scheme of the metal span structure $\mathrm{Ln}=44.0 \mathrm{~m}$ is shown in Fig. 2.

As a computational model, a spatial scheme was constructed from rod elements, where the elements were modeled according to their geometric dimensions, which made it possible to estimate the own weight of the girder structure, as well as the corresponding distribution by elements masses for further assessment of elements masses on forces redistribution.

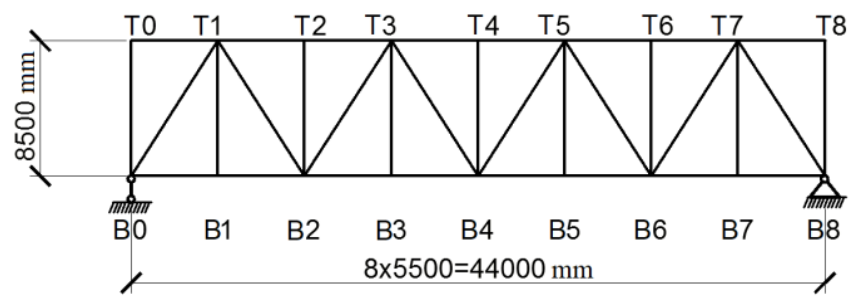

Figure 2

The scheme of the span structure $\mathrm{Ln}=44.0 \mathrm{~m}$

It is very important at this stage of research by simplifying the calculation scheme not to lose the features of the entire structure of the girder and, in particular, the bridge deck - significant simplifications are unacceptable $[10,11]$.

The calculations were performed using the finite element method in the Selena 4.1.1 software. The solution of this problem will make it possible to objectively assess the stress-strain state in which the stringers and floor beams of metal bridges with storey connection. The main goal is to identify the interaction in the 
operation of the beams with the elements of the truss and the influence of the continuity of the stringers on the stress-strain state of the floor beams.

As there is no possibility to set an addition weight of fastening elements, and also additional weight of hardware using this particular modeling, the overload factor from own weight was set as $10 \%$.

In accordance with the design, all elements were assigned the material of the girder structure Steel 3, which allowed not only to distribute the weight in accordance with the cross-sections (depending on the cross-sectional area and density of the material), but also to consider the system in terms of material's mechanical properties.

\section{Research of Deck Beams Work under Static Loading}

Determination of forces in the deck beams under the static load of the span structure with a length of $44.0 \mathrm{~m}$ was performed in accordance with field tests of the bridge over the river Mokra Moskovka on $186 \mathrm{~km}$ of the line Kryvyi Rih Volnovakha [12]. The load of the model is made according to the scheme of paired locomotives 2TE10. The scheme of static load of the locomotive 2TE10 is shown in Fig. 3, and schemes of loading for the research are shown in Fig. 4.

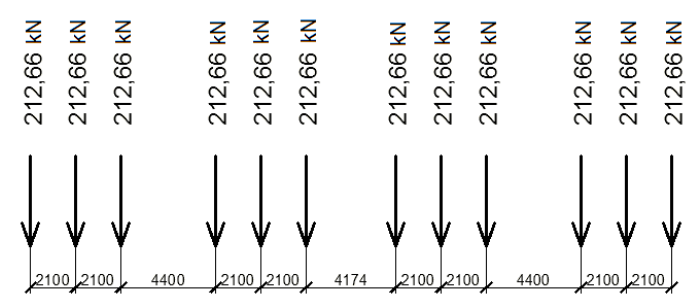

Figure 3

Scheme of static load model

The maximum values of the forces in the elements of the deck from the experimental load are shown in Tables 1 and 2.

As a result of the calculation, the fields of normal stresses along the $\mathrm{X}$ and $\mathrm{Y}$ axes, as well as the fields of tangential stresses were built. 


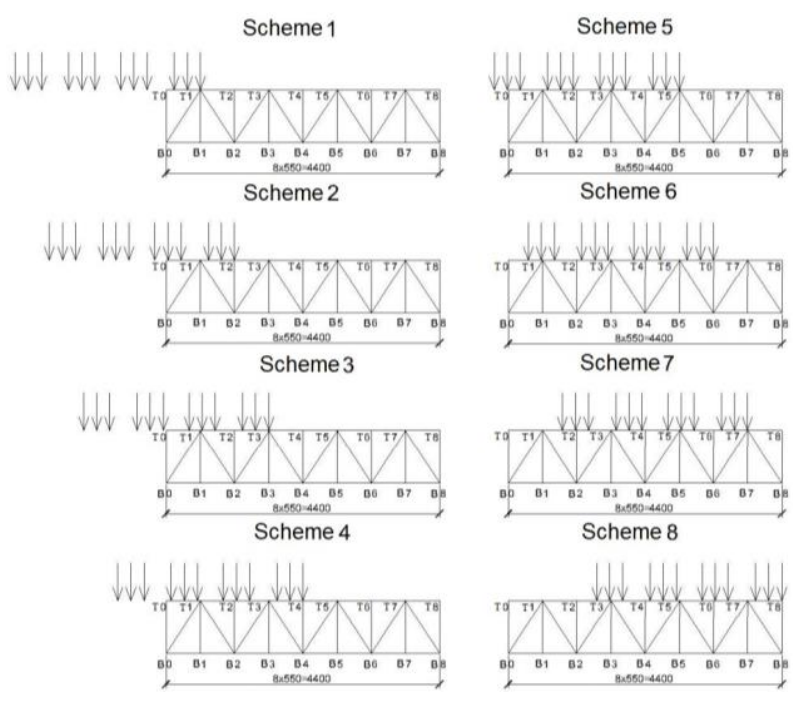

Figure 4

Schemes of loading of calculation model

Table 1

Bending moment (vertical) in the deck stringers, $\mathrm{kN} \cdot \mathrm{m}$

\begin{tabular}{|l|l|l|l|l|l|l|l|l|}
\hline \multirow{2}{*}{$\begin{array}{l}\text { Element } \\
\text { according } \\
\text { calculation } \\
\text { scheme }\end{array}$} & \multicolumn{6}{l}{ Schemes of experimental loading } \\
\cline { 2 - 9 } & №1 & №2 & №3 & №4 & №5 & №6 & №7 & №8 \\
\hline S0-1 & 153.6 & 94.3 & 80.3 & 142.5 & 79.7 & 104.9 & -54.6 & -14.2 \\
\hline S1-2 & -60.5 & 144.8 & 115.1 & 101.2 & 176.0 & 84.1 & 132.9 & -17.3 \\
\hline S2-3 & 2.7 & 16.5 & 155.4 & 138.6 & 93.2 & 178.1 & 109.1 & 148.5 \\
\hline S3-4 & 2.7 & -15.6 & -29.6 & 141.4 & 102.0 & 107.9 & 153.0 & 91.0 \\
\hline S4-5 & 1.35 & 8.3 & 7.1 & -1.6 & 157.7 & 120.6 & 86.3 & 148.4 \\
\hline S5-6 & 1.3 & 5.3 & 12.3 & 7.6 & -11.1 & 164.5 & 111.4 & 108.8 \\
\hline S6-7 & 1.2 & 5.2 & 11.0 & 17.4 & 20.1 & -43.2 & 137.1 & 105.3 \\
\hline S7-8 & -0.8 & -3.2 & -6.5 & -9.3 & -13.9 & -19.4 & -37.3 & 125.9 \\
\hline
\end{tabular}

As a result of the calculation, the fields of normal stresses along the $\mathrm{X}$ and $\mathrm{Y}$ axes, as well as the fields of tangential stresses were built.

Analyzing these results yielded several conclusions:

- for the final floor beam F0, which is most intensively included in the joint work with the truss chords, the most unfavorable installation of the test load was the one according to scheme 6 ; 
- maximum stresses occur in the floor beams of odd nodes F1, F7 (according to the loading schemes №5 and №6 for F1 and schemes №7 and №8 - for F7).

Table 2

Bending moment (vertical) in the floor beams of the deck, $\mathrm{kN} \cdot \mathrm{m}$

\begin{tabular}{|l|l|l|l|l|l|l|l|l|}
\hline $\begin{array}{l}\text { Element } \\
\text { according } \\
\begin{array}{l}\text { calculation } \\
\text { scheme }\end{array}\end{array}$ & \multicolumn{6}{|l|}{ Schemes of experimental loading } \\
\cline { 2 - 9 } & №1 & №2 & №3 & №4 & №5 & №6 & №7 & №8 \\
\hline F0 & 105.9 & 129.3 & 20.7 & 122.0 & 46.9 & 34.0 & -8.6 & 2.04 \\
\hline F1 & 148.2 & 216.8 & 253.3 & 241.8 & 229.9 & 249.1 & 66.5 & -6.56 \\
\hline F2 & -1.27 & 147.9 & 173.3 & 185.2 & 178.8 & 162.1 & 167.9 & 33.5 \\
\hline F3 & -1.58 & 6.01 & 186.7 & 211.3 & 226.6 & 231.1 & 200.8 & 240.4 \\
\hline F4 & -0.5 & -8.04 & -12.7 & 106.2 & 15.7 & 160.0 & 154.6 & 149.1 \\
\hline F5 & -0.6 & -1.75 & -6.2 & -4.7 & 177.8 & 202.1 & 216.1 & 209.2 \\
\hline F6 & -0.7 & -2.82 & -5.9 & -12.0 & 20.44 & 134.2 & 144.9 & 155.3 \\
\hline F7 & -0.06 & -0.08 & -0.007 & 0.3 & -1.4 & 9.3 & 191.8 & 216.5 \\
\hline F8 & 0.1 & 0.4 & 0.8 & 1.24 & 2.1 & -1.5 & -5.4 & 165.1 \\
\hline
\end{tabular}

During the field test of the span structure beams F1 and F7 were not subject to stress measurement because the largest number of defects (ruptures of rivets, weakening of bolts, cracks along the edge of the stringers' flange angles at the nodes, their connection to the floor beams) was observed on these beams and measuring stress on already broken structures is virtually pointless [12].

The highest stresses $\sigma \mathrm{x}$ in the flange angles of the floor beam F0 during the test reached +49.5 $\mathrm{MPa}$ (bottom) and $-63.7 \mathrm{MPa}$ (top), and the results of calculations are in the range from $+87 \mathrm{MPa}$ to $-84 \mathrm{MPa}$, which almost coincides with the field tests results (depends on the location of strain gages).

Comparing the obtained data with the results of a field experiment [12] shows a significant match, both in qualitative and quantitative terms of almost all results (Tables 3,4), which proves a high degree of reliability.

As it turned out, in the stringers the stress state does not exceed $100 \mathrm{MPa}$, and in the floor beams of the odd nodes F1 and F7 stresses significantly exceed the calculated strength of the material.

The reason for this is the inclusion of stringers in the joint work with the truss chords. It is believed that with spans of less than $60 \mathrm{~m}$, this phenomenon may be ignored because it reduces the forces in the chords by less than $10 \%$. At the same time, this slight force is transmitted through the floor beams to the stringers, causing not only the compression of later, but also the longitudinal bending with the torsion of the floor beams. 
Table 3

Comparison of test results and calculation for floor beams

\begin{tabular}{|l|l|l|l|l|l|l|l|l|l|}
\hline \multirow{2}{*}{$\begin{array}{l}\text { Loading } \\
\text { schemes }\end{array}$} & \multicolumn{3}{|l|}{ Beam F0 (top) } & \multicolumn{3}{l|}{ Beam F2 (top) } & \multicolumn{3}{l|}{ Beam F4 (top) } \\
\cline { 2 - 11 } & $\begin{array}{l}\text { Calc, } \\
\text { MPa }\end{array}$ & $\begin{array}{l}\text { Test, } \\
\mathrm{MPa}\end{array}$ & $\Delta, \%$ & $\begin{array}{l}\text { Calc, } \\
\mathrm{MPa}\end{array}$ & $\begin{array}{l}\text { Test, } \\
\mathrm{MPa}\end{array}$ & $\Delta, \%$ & $\begin{array}{l}\text { Calc, } \\
\mathrm{MPa}\end{array}$ & $\begin{array}{l}\text { Test, } \\
\mathrm{MPa}\end{array}$ & $\Delta, \%$ \\
\hline 1 & -21.50 & -21.2 & -1.4 & 3.60 & 3.8 & 5.3 & -36.00 & -42 & 14.3 \\
\hline 2 & -41.00 & -47.1 & 13.0 & 8.00 & 8 & 0.0 & -33.00 & -36.7 & 10.1 \\
\hline 3 & -41.20 & -41.5 & 0.7 & -22.00 & -24.5 & 10.2 & -9.00 & -9.8 & 8.2 \\
\hline 4 & -42.00 & -40.1 & -4.7 & -115.00 & -116.5 & 1.3 & -51.00 & -57.1 & 10.7 \\
\hline 5 & -60.50 & -63.7 & 5.0 & -105.00 & -99.5 & -5.5 & -32.00 & -36.8 & 13.0 \\
\hline 6 & -34.00 & -32.5 & -4.6 & -105.00 & -106.6 & 1.5 & -31.00 & -35.1 & 11.7 \\
\hline 8 & -22.00 & -22.6 & 2.7 & -93.00 & -94.5 & 1.6 & -29.00 & -32.7 & 11.3 \\
\hline
\end{tabular}

Table 4

Comparison of test results and calculation for stringers

\begin{tabular}{|l|l|l|l|l|l|l|l|l|l|}
\hline \multirow{2}{*}{\multicolumn{2}{|c|}{ Beam }} & \multicolumn{6}{|l|}{ Loading schemes } \\
\cline { 3 - 11 } \multicolumn{2}{|l|}{} & 1 & 2 & 3 & 4 & 5 & 6 & 7 & 8 \\
\hline \multirow{3}{*}{$\begin{array}{l}\text { S1- } \\
2\end{array}$} & Calc, Mpa & -3.6 & 11.0 & 13.5 & 12.75 & 15.0 & 10.8 & 20.0 & -7.8 \\
\cline { 2 - 11 } & Test, MPa & -3.5 & 10.4 & 13.3 & 12.8 & 15 & 10.9 & 19.7 & -8.6 \\
\cline { 2 - 11 } & $\Delta, \%$ & -2.9 & -5.8 & -1.5 & 0.4 & 0 & 0.9 & -1.5 & 9.3 \\
\hline
\end{tabular}

The total values of stresses $\sigma \mathrm{x}$ in the beams are shown in the graphs, Figures 5-8.

The appearance of unacceptable overstress, which lead to cracks and other defects, significantly reduce the durability and bearing capacity of the span structures of railway bridges in operation.

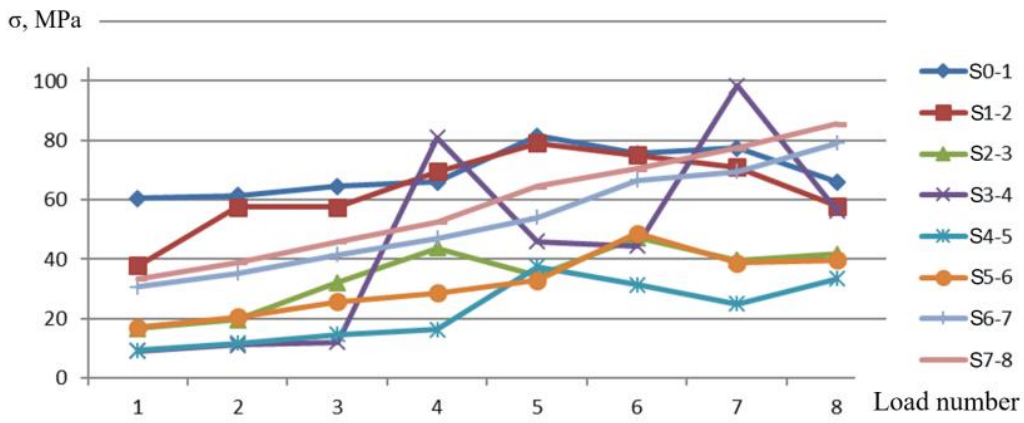

Figure 5

Total positive values of normal stresses in the deck stringers, $\mathrm{MPa}$ 


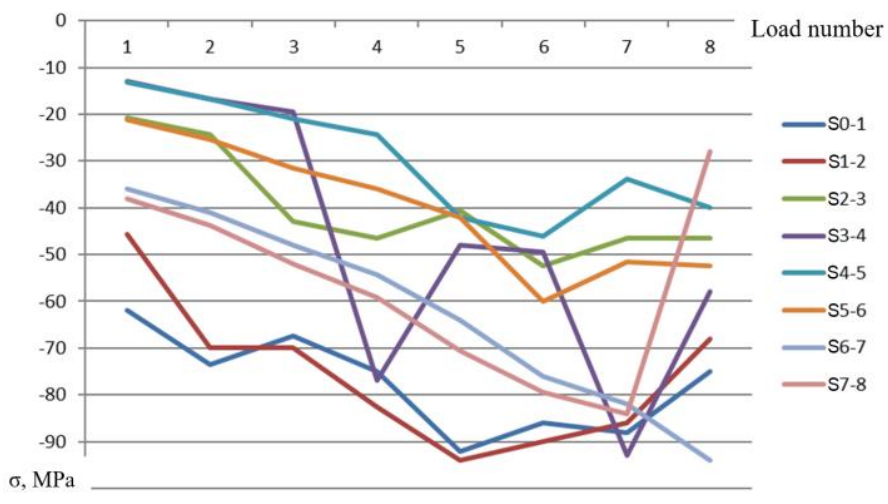

Figure 6

Total negative values of normal stresses in the deck stringers, MPa

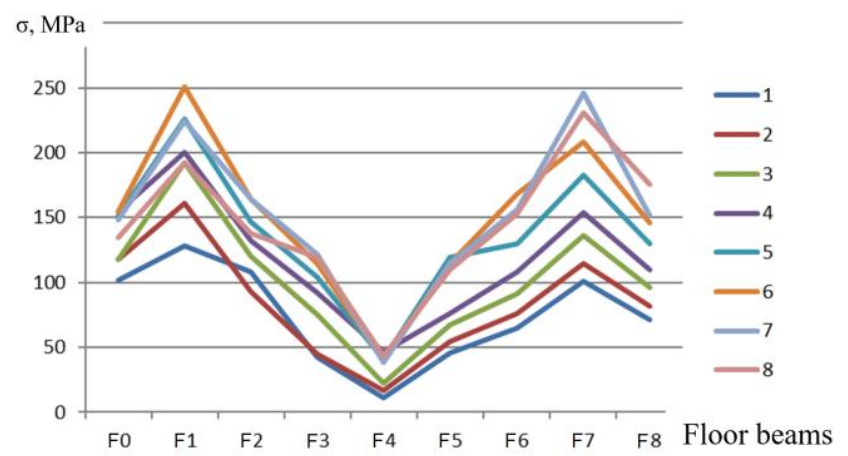

Figure 7

Total positive values of normal stresses in the deck floor beams, MPa

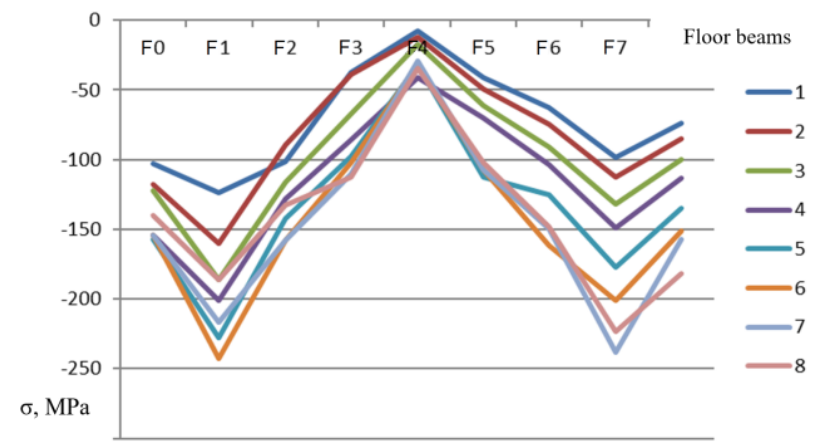

Figure 8

Total negative values of normal stresses in the deck floor beams, MPa 


\section{Conclusions}

1) In almost all nodes of the support of the stringers on the floor beams of the studied span structures there is an excess of the calculated resistance of the material of the girder structures - steel St 3 and in many the yield point of material is exceeded, especially in nodes where on the carried-out inspections demonstrated bearing disorders.

2) According to the results of calculations and computer simulations, it is determined that the main cause of cracks is the structural imperfection of the bearing nodes of the stringers on the floor beams of the span structure with a storey deck, that is typical for similar structures.

3) The main factor that causes the appearance of defects is the bending moment in the floor beam relative to the axis of the stringer, which due to the transfer of forces to a small area of the rivet joint leads to significant stresses in the lower edge of the bottom flange angles of the stringers. Such an occurrence is possible when the rivet joint is defect and is associated with residual deformations of the flange angles in the stringer and floor beam from the cyclic load.

4) With increasing span length and, accordingly, increasing forces in the support nodes of the stringers on the floor beams, the stress and the probability of cracks in the bottom flange angles of the stringers increases too.

5) The presence of significant main stresses in the nodes, where there are no obvious cracks may indicate the presence of hidden defects, which requires additional examination and study.

6) Analysis of the stress-strain state of the existing structure of the support node of the stringers on the floor beams indicates the complex operating conditions of the beams. Stresses in the horizontal edges of the angles reach 230-330 MPa, which significantly exceeds the calculated values of metal resistance.

\section{References}

[1] Kliuchnyk S. V.: Analysis of the current state of metal girder structures of railway bridges, Bridges and tunnels: Theory, Research, Practice. Collection of scientific works of Dnipropetrovsk National University of Railway Transport named after Academician V. Lazaryan, 12, 2017, pp. 29-40 [in Ukrainian]

[2] Soldatov K. I. and Blokhyn S. Y.: Course on strengthening and reconstruction of the operated artificial constructions of the railways of Ukraine, Bulletin of Dnipropetrovsk National University of Railway Transport, 33, 2010, pp. 262-271 [in Russian]

[3] Bychkovskij N. N and Dankovcev A. F.: Steel bridges, Saratov, 2005, 363 p. [in Russian] 
[4] Kliuchnyk S. V. and Marochka V. V.: Experience in operating a storey bridgedeck, Abstracts of the $72^{\text {nd }}$ International Scientific and Practical Conference "Problems and Prospects for the Development of Railway Transport", Dnipropetrovsk, Ukraine, 2012, p. 158 [in Russian]

[5] Kliuchnyk S. V. and Marochka V. V.: Review of options for reinforcement and repair of storey type bridgedeck beams, Bridges and tunnels: Theory, Research, Practice. Collection of scientific works of Dnipropetrovsk National University of Railway Transport named after Academician V. Lazaryan, 5, 2014, pp. 35-40 [in Ukrainian]

[6] András Bakó and László Gáspár.: Development of a Sustainable Optimization Model for the Rehabilitation of Transport Infrastructure, Acta Polytechnica Hungarica, Vol. 15, No. 1, 2018, pp. 11-33

[7] Németh, A. and Fischer, S.: Investigation of the glued insulated rail joints applied to cwr tracks, Facta Universitatis Series Mechanical Engineering, online first, 2021

[8] DBN B.2.3-14:2006. Transport structures. Bridges and pipes. Design rules., Kyiv: Ministry of Construction, Architecture and Housing, 2006, 359 p. [in Ukrainian]

[9] DBN B.2.3-26:2010 Transport structures. Bridges and pipes. Steel structures. Design rules. Part 1, 2., Kyiv: National Transport University, 2011, 108 p. [in Ukrainian]

[10] Vaszilievits-Sömjén, B., Szalai, J., Movahedi, R. M.: Warping transfer superelement model for bolted end-plate connections subject to 3D loads, SDSS 2019 - International Colloquium on Stability and Ductility of Steel Structures, 2019

[11] Xin Chen, Nao-Aki Noda, Magd Abdel Wahab, Yu-Ichiro Akaishi, Yoshikazu Sano, Yasushi Takase, Gusztáv Fekete: Fatigue Failure Analysis for Bolt-Nut Connections having Slight Pitch Differences using Experimental and Finite Element Methods, Acta Polytechnica Hungarica, Vol. 12, No. 8, 2015, pp. 61-79

[12] Kluchnik S. V.: «Stress-strain state of beam staged connection point of the railway bridge track-way» Science and Transport Progress. Bulletin of Dnipropetrovsk National University of Railway Transport, 3 (69), 2017, pp. $160-170$ 